\title{
Increased neurogenesis after hypoxic-ischemic encephalopathy in humans is age related
}

\author{
Wulf-Rainer C. Mattiesen · Simone C. Tauber • \\ Joachim Gerber $\cdot$ Stephanie Bunkowski . \\ Wolfgang Brück $\cdot$ Roland Nau
}

Received: 11 November 2008 / Revised: 1 February 2009 / Accepted: 27 February 2009 / Published online: 11 March 2009

(C) The Author(s) 2009. This article is published with open access at Springerlink.com

\begin{abstract}
The leading cause of morbidity and mortality after successful resuscitation is hypoxic-ischemic encephalopathy (HIE), which results in neuronal loss within the neocortex and the hippocampal formation. This study focuses on the impact of HIE on adult neurogenesis in the human hippocampal dentate gyrus as a potential intrinsic regenerative mechanism in response to neuronal damage. Brain sections of 22 autopsy cases with HIE and of 19 agematched controls without neuropathological abnormalities were investigated by means of immunohistochemistry. The densities of immature granule cells during axon guidance and outgrowth (assessed by TUC-4 immunohistochemistry) and of young calretinin-expressing postmitotic neurons were increased in the granule cell layer of cases who had suffered from HIE $(P=0.0002$ and $P=0.0001$, respectively). Similarly, the density of apoptotic granule cells, as detected by in situ tailing and morphological criteria, was increased in HIE $(P=0.014)$. In cases with HIE, the increase in the density of TUC-4-labeled cells inversely correlated with age $(P=0.027)$. In contrast, neither the
\end{abstract}

W.-R. C. Mattiesen and S. C. Tauber have equally contributed to this work.

W.-R. C. Mattiesen · S. C. Tauber - J. Gerber ·

S. Bunkowski $\cdot$ R. Nau

Department of Neurology,

Georg-August-University, Göttingen, Germany

W. Brück

Department of Neuropathology,

Georg-August-University, Göttingen, Germany

R. Nau $(\bowtie)$

Department of Geriatrics,

Evangelisches Krankenhaus Göttingen-Weende,

An der Lutter 24, 37075 Göttingen, Germany

e-mail: rnau@gwdg.de density of proliferating nor that of apoptotic cells was substantially influenced by age within the control group. Taken together, both an increase in adult neurogenesis and in neuronal apoptosis was observed in the human dentate gyrus in response to HIE. The data suggest a decrease of adult neurogenesis in older-aged cases. Whether neurogenesis can contribute to recovery after HIE remains to be determined. The stimulation of adult neurogenesis may be less efficient in older victims of HIE.

Keywords Neurogenesis · Apoptosis · Human · Dentate gyrus · Hypoxic-ischemic encephalopathy · Age

\author{
Abbreviations \\ 4VO Four vessel occlusion \\ HIE Hypoxic-ischemic encephalopathy \\ IST In situ tailing \\ NSC Neural stem cells \\ PCNA Proliferating cell nuclear antigen \\ TUC-4 TOAD-64/Ulip/CRMP-4
}

\section{Introduction}

Hypoxic-ischemic encephalopathy (HIE) is one of the major complications in emergency medicine and obstetrics $[4,67,70,71]$. It can be caused by prolonged mechanical resuscitation, respiratory insufficiency as well as arterial hypotension or shock. It is the leading cause of morbidity and mortality occurring after successful resuscitation of cardiac arrest [29, 32]. The harmful effects of HIE are most severe in the hippocampus, neocortex, and cerebellum [29]. Whether these areas are most affected because of a border zone problem of cerebral perfusion is still a matter of debate. Nearly all patients with HIE remain in permanent 
need of care, $40 \%$ enter a persistent vegetative state [30] and after 1 year approximately $80 \%$ have died [29]. Current treatment includes intensive care medicine and rehabilitative therapy [61]. Since 2002, mild hypothermia for at least $24 \mathrm{~h}$ is recommended after cardiac arrest [60, 72].

Until 1960, adult neurogenesis was regarded as nonexistent [16]. Since then, different new methods have verified the proliferation of neural progenitor cells and their differentiation into mature neurons within the granule cell layer of the hippocampal dentate gyrus in both adult mammalian $[1,9,17,19,22,25,38,48,53,64]$ and human brains $[2,3$, $6,12,21,31,37,52,56]$.

Neural stem cells (NSC) are located in the subgranular layer of the dentate gyrus [24, 38] where a specific microenvironment exists that is considered to be crucial for neural proliferation [51]. Neuronal precursor cells are probably generated in clusters $[22,25,53]$ and migrate a short distance to their designated destination: the granule cell layer of the dentate gyrus [54]. However, whether their integration and differentiation into mature neurons is of functional significance is still a matter of debate [17, 22, 48, 64]. In rodents, a decrease of the magnitude of hippocampal neurogenesis with increasing age is well known [9, 19, 25, 42]. However, recent data suggest that hippocampal neurogenesis in rats appears to remain relatively unaltered in adulthood [18]. In humans, adult neurogenesis was increased in various neurological diseases of different pathophysiology such as Alzheimer's disease [2], multiple sclerosis [6], subarachnoidal hemorrhage [52], primary intracerebral hemorrhage [56] and epilepsy [15] while hippocampal neurogenesis was shown to be reduced in patients who underwent radiation therapy for central nervous system malignancies [37]. These observations suggest that enhancement of adult neurogenesis in humans may not be a uniform phenomenon, but a differently regulated event depending on the underlying condition [28, 44].

Whether adult neurogenesis is affected in response to HIE is not yet known. This is of interest, since the administration of neuroprotective drugs which interfere with adult neurogenesis and apoptosis and stimulate proliferation and migration of neuronal progenitor cells may be a potential therapeutic option. Recently, two infants with HIE caused by prolonged cardiopulmonary arrest received an intraventricular infusion of nerve growth factor. Improvement of their neurological condition and of cerebral perfusion, as well as an increase of doublecortin expression in the cerebrospinal fluid, were noted [8]. Other potential neuroprotective drugs may be fibroblast growth factor [38], epidermal growth factor [43], heparin-binding EGF-like growth factor [20], granulocyte colony-stimulating factor [35, 46], erythropoietin [57], inhibitors of vascular endothelial growth factor receptor [23], inducible nitric oxide synthase [74], statins [7], antidepressants [11, 45] and sildenafil [73].
The present study is designed to determine whether any change in neuronal proliferation, differentiation or apoptosis occurs in response to HIE. Furthermore, the study investigates whether these effects depend on the patients' age.

\section{Autopsy cases and methods}

\section{Autopsy cases}

In this retrospective study, autopsy cases from the Department of Neuropathology, Georg-August-University, Göttingen, Germany, were selected from 1996 to 2004 according to the following criteria: patients that had suffered from a clinically observed and neuropathologically confirmed HIE which had taken place at least $24 \mathrm{~h}$ before death and age-matched control cases. Exclusion criteria were stroke, death subsequent to a neurological disease, sepsis, cancer that had been treated with cytostatic agents or radiation before death, and forensic cases.

The HIE group consisted of 22 subjects ( 9 women, 13 men, median age 64 years, age span $35-85$ years) who had later died because of heart failure in 11 cases, because of respiratory insufficiency in 4 cases, because of failure of central regulation in 4 cases and because of shock in 3 cases (Table 1). HIE took place a median 10 days before death (range 1-53 days) because of prolonged mechanical resuscitation (13 cases), acute pulmonary decompensation (6 cases) or acute coronary syndrome (3 cases) (Table 1).

The control group consisted of 19 subjects ( 7 women, 12 men, median age 59 years, age span 35-81 years) whose causes of death were either sudden heart failure (16 cases), asphyxia (2 cases) or shock (one case) (Table 2). Resuscitation was attempted in 11 cases but, in contrast to the HIE group, death had occurred within $1.5 \mathrm{~h}$ after start of resuscitation. The cerebral hypoxia before death could have resulted in neuronal damage but all control cases lacked neuropathological abnormalities, particularly no evidence of HIE was detected (Table 2). Routine neuropathological examinations were performed by the Department of Neuropathology, Georg-August-University, Göttingen, Germany. The study was approved by the Ethics Committee of the Medical Faculty of the Georg-August-University in Göttingen, Germany.

Immunohistochemistry

Sections of the hippocampal formation were stained immunohistochemically for the cell proliferation maker proliferating cell nuclear antigen (PCNA) [26, 33], for TUC-4 (TOAD-64/Ulip/CRMP-4) as a marker for immature granule cells during axon guidance and outgrowth $[36,41,50$, 66] and for calretinin as a marker for young postmitotic 
Table 1 Information about HIE cases

\begin{tabular}{|c|c|c|c|c|c|c|c|}
\hline Age & Sex & Cause of death & $\begin{array}{l}\text { Neuropathological } \\
\text { diagnosis }\end{array}$ & Cause of HIE & Interval $1^{\mathrm{a}}$ & Interval $2^{\mathrm{b}}$ & Interval $3^{c}$ \\
\hline 35 & $\mathrm{~F}$ & Failure of central regulation & HIE & Prolonged mechanical resuscitation & 4 & 1 & 11 \\
\hline 35 & $\mathrm{~F}$ & Failure of central regulation & HIE & Acute pulmonary decompensation & 2 & 1 & 10 \\
\hline 42 & M & Sudden heart failure & HIE & Prolonged mechanical resuscitation & 30 & 5 & 9 \\
\hline 42 & M & Sudden heart failure & HIE & Prolonged mechanical resuscitation & 53 & 3 & 11 \\
\hline 44 & $\mathrm{~F}$ & Failure of central regulation & HIE & Prolonged mechanical resuscitation & 8 & 2 & 4 \\
\hline 48 & M & Sudden heart failure & HIE & Prolonged mechanical resuscitation & 11 & 1 & 11 \\
\hline 52 & M & Respiratory insufficiency & HIE & Acute pulmonary decompensation & 26 & 1 & 4 \\
\hline 55 & M & Respiratory insufficiency & HIE & Prolonged mechanical resuscitation & 8 & 3 & 8 \\
\hline 55 & M & Sudden heart failure & HIE & Prolonged mechanical resuscitation & 21 & 2 & 6 \\
\hline 61 & M & Respiratory insufficiency & HIE & Prolonged mechanical resuscitation & 59 & 5 & 4 \\
\hline 63 & M & Sudden heart failure & HIE & Acute coronary syndrome & 24 & 5 & 11 \\
\hline 64 & M & Sudden heart failure & HIE & Prolonged mechanical resuscitation & 19 & 1 & 5 \\
\hline 72 & $\mathrm{~F}$ & Sudden heart failure & HIE & Acute pulmonary decompensation & 21 & 3 & 4 \\
\hline 73 & $\mathrm{~F}$ & Shock & HIE & Acute coronary syndrome & 1 & 1 & 3 \\
\hline 73 & M & Sudden heart failure & HIE & Prolonged mechanical resuscitation & 15 & 1 & 6 \\
\hline 74 & M & Shock & HIE & Prolonged mechanical resuscitation & 1 & 0 & 9 \\
\hline 75 & $\mathrm{~F}$ & Sudden heart failure & HIE & Prolonged mechanical resuscitation & 1 & 1 & 9 \\
\hline 76 & $\mathrm{~F}$ & Sudden heart failure & HIE & Prolonged mechanical resuscitation & 1 & 1 & 6 \\
\hline 80 & $\mathrm{~F}$ & Shock & HIE & Acute pulmonary decompensation & 2 & 1 & 11 \\
\hline 81 & M & Sudden heart failure & HIE & Acute pulmonary decompensation & 3 & 2 & 11 \\
\hline 83 & M & Respiratory insufficiency & HIE & Acute pulmonary decompensation & 18 & 2 & 3 \\
\hline 85 & $\mathrm{~F}$ & Failure of central regulation & HIE & Acute coronary syndrome & 2 & 1 & 9 \\
\hline
\end{tabular}

neurons [5, 49]. One section was stained per each marker and case. The formalin-fixed, paraffin-embedded brain tissue was cut in 2- $\mu \mathrm{m}$-thick sections, dried, deparaffinizied and pretreated with $15 \mathrm{~min}$ of microwaving in citric acid buffer (10 mmol/L, pH 6.0).

PCNA and calretinin stainings were performed in phosphate-buffered saline; after treating with $3 \% \mathrm{H}_{2} \mathrm{O}_{2}$ for $10 \mathrm{~min}$ and blocking with $10 \%$ fetal calf serum for $30 \mathrm{~min}$, monoclonal mouse anti-PCNA antibody (1:200, Chemicon, Temecula, CA, USA) or polyclonal rabbit anti-calretinin antibody (1:1,000, Swant, Bellinzona, Switzerland) were allowed to bind for $120 \mathrm{~min}$ at room temperature. The primary antibodies were detected by biotinylated sheep antimouse antibody (1:200, Amersham, Buckinghamshire, UK) or biotinylated donkey anti-rabbit antibody (1:200, GE Healthcare, Buckinghamshire, UK). Avidin peroxidase (Sigma-Aldrich, St. Louis, MO, USA) was used as conjugated enzyme and DAB (Roche, Mannheim, Germany) as chromogenic substrate.

TUC-4 staining was performed in Tris-buffered saline; after blocking with $10 \%$ fetal calf serum for $30 \mathrm{~min}$, polyclonal rabbit anti-TUC-4 antibody (1:200, Chemicon,
Temecula, CA, USA) was allowed to bind overnight at $4{ }^{\circ} \mathrm{C}$. Detection was carried out by means of a monoclonal mouse anti-rabbit antibody (1:50, Dako, Kopenhagen, Denmark), a rabbit anti-mouse antibody (1:50, Dako, Kopenhagen, Denmark) and alkaline phosphatase anti-alkaline phosphatase complex (1:50, Dako, Kopenhagen, Denmark). Newfuchsin (Dako, Kopenhagen, Denmark) was used as chromogenic substrate.

All sections were counterstained with hemalum (Merck, Darmstadt, Germany). Control sections were treated similarly, with or without primary antibodies.

Apoptotic granule cells

Apoptotic granule cells in the dentate gyrus were detected by in situ tailing (IST) of fragmented deoxyribonucleic acid combined with the use of morphological criteria (condensed, shrunken nucleus and narrow cytoplasm) [14, 39]. For IST, brain tissue was cut, dried, and deparaffinizied as described above. The sections were first incubated with $100 \mu \mathrm{g} / \mathrm{ml}$ proteinase K (Sigma-Aldrich, St. Louis, MO, USA) at $37^{\circ} \mathrm{C}$ for $15 \mathrm{~min}$, followed 
Table 2 Information about control cases

\begin{tabular}{|c|c|c|c|c|c|c|}
\hline Age & Sex & Cause of death & Neuropathological diagnosis & Resuscitation & Interval $2^{\mathrm{a}}$ & Interval $3^{\mathrm{b}}$ \\
\hline 35 & M & Sudden heart failure & Age-dependent normal brain & Attempted $<1 \mathrm{~h}$ before death & 3 & 2 \\
\hline 36 & M & Sudden heart failure & Age-dependent normal brain & Attempted $<1 \mathrm{~h}$ before death & 0 & 2 \\
\hline 39 & M & Asphyxia & Age-dependent normal brain & None & 5 & 6 \\
\hline 43 & M & Shock & Age-dependent normal brain & Attempted $1.5 \mathrm{~h}$ before death & 0 & 5 \\
\hline 45 & M & Sudden heart failure & Age-dependent normal brain & Attempted $<1 \mathrm{~h}$ before death & 1 & 5 \\
\hline 47 & M & Asphyxia & Age-dependent normal brain & Attempted $2 \mathrm{~h}$ before death & 1 & 5 \\
\hline 48 & $\mathrm{~F}$ & Sudden heart failure & Age-dependent normal brain & None & 1 & 4 \\
\hline 51 & $\mathrm{~F}$ & Sudden heart failure & Age-dependent normal brain & Attempted $<1 \mathrm{~h}$ before death & 3 & 7 \\
\hline 58 & $\mathrm{~F}$ & Sudden heart failure & Age-dependent normal brain & Attempted $<1 \mathrm{~h}$ before death & 2 & 6 \\
\hline 59 & M & Sudden heart failure & Age-dependent normal brain & Attempted $<1 \mathrm{~h}$ before death & 0 & 6 \\
\hline 65 & M & Sudden heart failure & Age-dependent normal brain & Attempted $<1 \mathrm{~h}$ before death & 2 & 2 \\
\hline 67 & $\mathrm{~F}$ & Sudden heart failure & Age-dependent normal brain & None & 1 & 4 \\
\hline 68 & $\mathrm{~F}$ & Sudden heart failure & Age-dependent normal brain & None & 3 & 6 \\
\hline 70 & M & Sudden heart failure & Age-dependent normal brain & Attempted $1.5 \mathrm{~h}$ before death & 2 & 3 \\
\hline 71 & M & Sudden heart failure & Age-dependent normal brain & None & 1 & 2 \\
\hline 73 & M & Sudden heart failure & Age-dependent normal brain & None & 0 & 6 \\
\hline 74 & $\mathrm{~F}$ & Sudden heart failure & Age-dependent normal brain & None & 0 & 6 \\
\hline 79 & M & Sudden heart failure & Age-dependent normal brain & Attempted $<1 \mathrm{~h}$ before death & 3 & 3 \\
\hline 81 & $\mathrm{~F}$ & Sudden heart failure & Age-dependent normal brain & None & 1 & 7 \\
\hline
\end{tabular}

${ }^{a}$ Interval from death to fixation (days)

b Age of the paraffin-embedded brain sections (years)

by incubation with a tailing mixture of $10 \mu \mathrm{l}$ tailing buffer, $1 \mu 1$ digoxigenin deoxyribonucleic acid labeling mix, $2 \mu \mathrm{l}$ cobalt chloride, $0.5 \mu \mathrm{l}$ terminal transferase (all Roche, Mannheim, Germany) ad $50 \mu$ distilled water for $60 \mathrm{~min}$ and additionally with $10 \%$ FCS for $20 \mathrm{~min}$ at $37^{\circ} \mathrm{C}$. Finally, sheep anti-digoxigenin antibody (FAB fragments, 1:250, Roche, Mannheim, Germany) in Trisbuffered saline was allowed to bind for $120 \mathrm{~min}$ at room temperature. 4-Nitroblue-tetrazoliumchloride/5-bromine-4chloride-3-indolylphosphate was used as chromogenic substrate. The sections were counterstained with nuclear fast red-aluminium hydroxide (Roche, Mannheim, Germany). Negative control sections were treated similarly but without tailing mixture or the anti-digoxigenin antibody. As positive controls, sections of the hippocampal formation of a newborn marmoset monkey with a high rate of apoptotic neurons were used.

\section{Light microscopy}

All sections were inspected by light microscopy (BX 51 TF, Olympus, Hamburg, Germany) equipped with digital camera technology (ColorView II Camera Set, Olympus Hamburg, Germany, Workstation Standard, Soft Imaging System, Münster, Germany). The area of the dentate gyrus (granule cell layer and border of the subgranular layer) was determined by planimetry with the software AnalySIS 3.2
(Soft Imaging System, Münster, Germany). The numbers of immunoreactive cells within the determined areas were counted by a blinded investigator at a magnification of $60 \times$. The cell densities were expressed as number of immunoreactive cells per $\mathrm{mm}^{2}$ of measured area.

\section{Statistical analysis}

Data are presented as box-whisker plots with maximum, 75th percentile, median, 25th percentile and minimum and were compared by Mann-Whitney's two-tailed nonparametric $U$ test. The relation between the density of immunoreactive cells and the age of the patient was assessed with Spearman's nonparametric two-tailed rank correlation. All statistical analyses were carried out using GraphPad Prism Software version 4 (GraphPad Software, San Diego, CA, USA). A $P$ value of $<0.05$ was considered statistically significant.

\section{Results}

In this study, firstly an HIE group was compared to a control group with normal brains regarding precursor cell proliferation, expression of TUC-4 and calretinin and density of apoptotic granule cells. Secondly, these parameters were related to the age of the autopsy cases in both groups. 
Neither in HIE nor in control cases, was the density of the immunoreactive cells of any marker used in this study correlated with the intervals from death to fixation. The age of the paraffin blocks also did not correlate with the densities of immunoreactive cells for any stainings employed in this study (Tables 1, 2). No statistically significant relations were noted between recent corticosteroid treatment, depression, or the presence or absence of previously untreated malignant disease (found accidentally at autopsy) and the densities of immunoreactive cells. In those cases of the control group where resuscitation was attempted, death did occur within $1 \mathrm{~h}$ after start of resuscitation and no differences in proliferation, neurogenesis or apoptosis in the dentate gyrus were detected compared to control cases without a history of resuscitation.

Precursor cell proliferation in the dentate gyrus after HIE

The proliferation of putative neuronal precursor cells in the dentate gyrus was determined by staining with the proliferation marker PCNA, an intranuclear cofactor of deoxyribonucleic acid polymerase delta in rats [33] that is expressed from the $\mathrm{G} 1$ phase to the $\mathrm{G} 2 / \mathrm{M}$ transition of cell division in humans [26]. The median density $\left(/ \mathrm{mm}^{2}\right)$ of proliferating cells in the granule cell layer of the dentate gyrus was higher in the HIE group (factor of 3.66) in comparison to controls (Fig. 1). However, the difference failed to reach statistical significance $(P=0.086)$. Stained cells were approximately evenly distributed within the dentate gyrus (Fig. 2a).

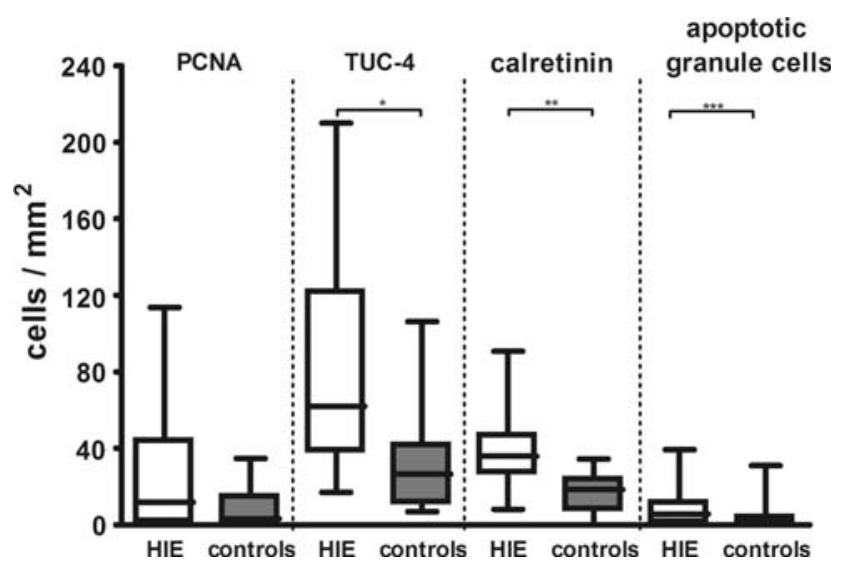

Fig. 1 Comparison of densities $\left(/ \mathrm{mm}^{2}\right)$ of immunoreactive cells for the proliferation marker PCNA, of immature granule cells during axon guidance and outgrowth (TUC-4) and of young postmitotic neurons (calretinin) as well as apoptotic granule cells in the dentate gyrus in cases with HIE and controls with normal brains. Both the density of TUC-4- and of calretinin-labeled young neuronal cells as well as apoptotic granule cells were significantly increased in subjects with HIE in comparison to controls $(* P=0.0002, * * P=0.0001$, $* * * P=0.014)$. Data are presented as box-whisker plots (maximum, 75th percentiles, medians, 25th percentiles, minimum)
Increased expression of TUC-4 and calretinin in the dentate gyrus after HIE

The densities of both immature granule cells during axon outgrowth (assessed by TUC-4 immunohistochemistry) and young calretinin-expressing postmitotic neurons were significantly increased in the subgranular and granule cell layer of the dentate gyrus in subjects with HIE.

TUC-4 is expressed in immature granule cells and involved in axon guidance and outgrowth in humans [41], and in rats most probably from the first to the fourth week after mitosis $[36,50]$. In the present study, TUC-4-labeled cells were mainly located in the subgranular layer of the dentate gyrus while only a few were located in the granule cell layer of the dentate gyrus (Fig. 2b). Their median density was significantly increased by 2.33 times in the HIE group in comparison to controls $(P=0.0002)$ (Fig. 1).

Calretinin is a calcium-binding protein that is expressed in young postmitotic neurons of mice for up to 6 weeks [5, 49]. Immunoreactive cells were most frequently located in the subgranular layer of the dentate gyrus (Fig. 2c). The median density of calretinin-labeled cells was significantly increased by 1.95 times in subjects with HIE in comparison to controls $(P=0.0001)$ (Fig. 1). In a sample of five cases with HIE, analysis of serial sections stained by calretinin and TUC-4 revealed that $11.7 \%$ of 162 calretinin-labeled cells expressed TUC-4 in the adjacent section, suggesting the coexpression of both markers.

Increased density of apoptotic granule cells after HIE

IST and morphological criteria (condensed, shrunken nucleus and narrow cytoplasm) [14] were used to detect apoptotic granule cells [39] (Fig. 2d). Apoptotic granule cells were mainly located at the border of the subgranular and granule cell layer. In HIE cases, in median $19.5 \%$ of all ISTpositive cells showed an apoptotic morphology (range, 0 $45.5 \%$ ). The density of apoptotic granule cells in autopsy cases with HIE was significantly higher than in subjects without neuropathological abnormalities $(P=0.014)$ (Fig. 1). Regarding apoptotic granule cells, no factor of augmentation could be calculated, because a median of 0 apoptotic granule cells $/ \mathrm{mm}^{2}$ was detected in control subjects (Fig. 1).

Densities of immunoreactive cells as related to the age of the patients

\section{No correlation of proliferating cells with age}

Within the HIE group the density of PCNA-labeled cells remained approximately constant and did not change significantly with increasing age (Table 3a). Similarly, there was no correlation between the density of proliferating cells 
Fig. 2 Light photomicrographs of the dentate gyrus of humans with HIE. Expression of the proliferation marker PCNA (a) in a 73-year-old woman after death caused by shock and from acute coronary syndrome the day before. Staining of immature TUC4 immunoreactive granule cells (b) in a 73-year-old man after death due to heart failure after prolonged mechanical resuscitation 15 days before. Young calretinin-labeled postmitotic neurons (c) in a 61-year-old man after death because of respiratory arrest after prolonged mechanical resuscitation 59 days before. Apoptotic granule cell with typical morphology labeled by in situ tailing (d) in an 81-year-old man after death because of respiratory arrest after prolonged mechanical resuscitation 3 days before. Scale bar $50 \mu \mathrm{m}$
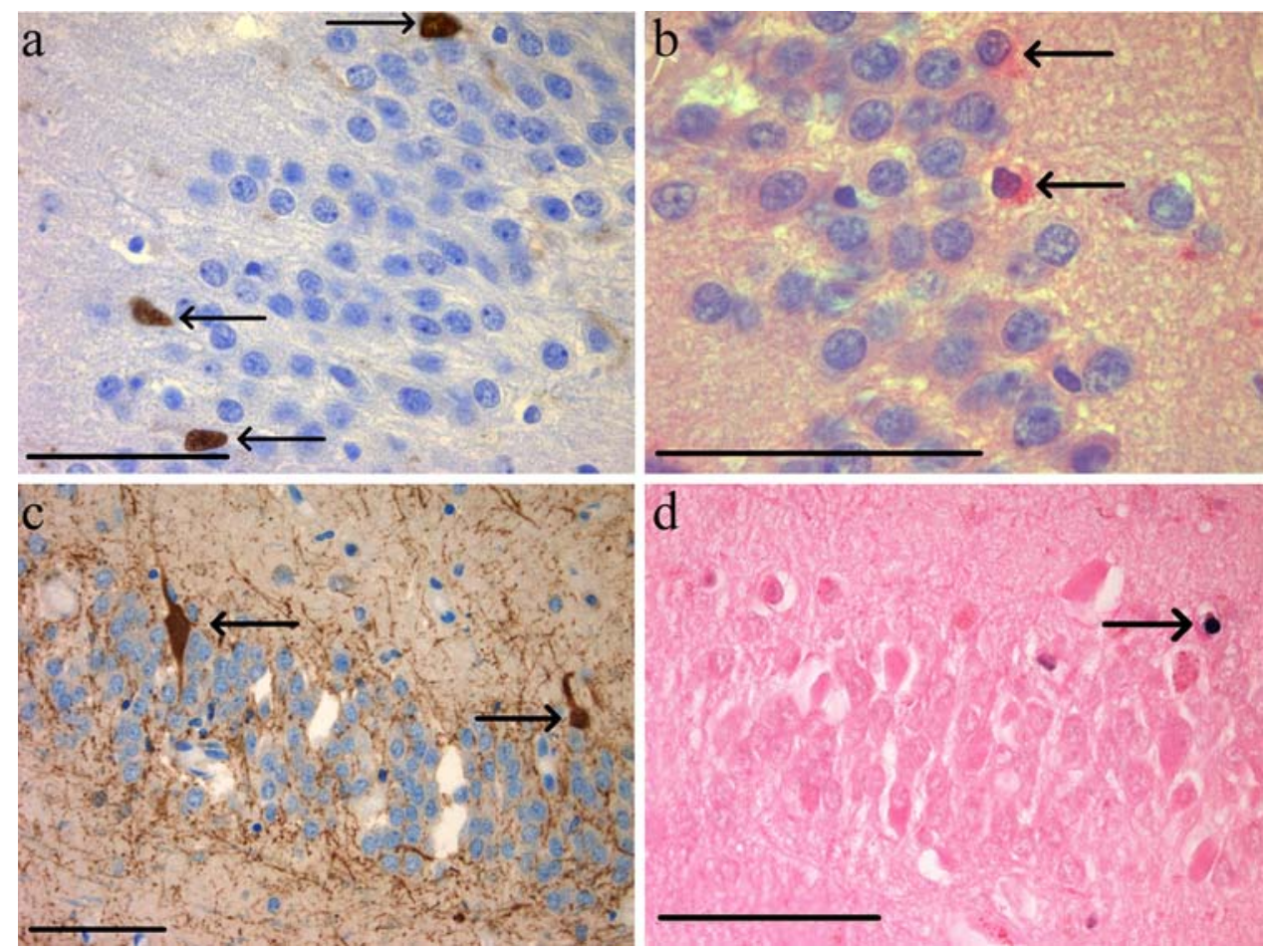

Table 3 Relation between age at death and the density of immunoreactive cells or apoptotic granule cells, respectively, and as calculated by Spearman's rank correlation in: (a) cases with HIE, (b) controls

Spearman's rank
correlation coefficient

\section{(a) HIE}

\begin{tabular}{lrl} 
PCNA & -0.03 & 0.89 \\
TUC-4 & -0.47 & $\mathbf{0 . 0 3}$ \\
Calretinin & -0.41 & 0.06 \\
Apoptotic granule cells & -0.37 & 0.09 \\
(b) Control & & \\
PCNA & 0.12 & 0.63 \\
TUC-4 & 0.23 & 0.35 \\
Calretinin & -0.12 & 0.63 \\
Apoptotic granule cells & 0.17 & 0.48 \\
\hline
\end{tabular}

In cases with HIE, the density of immature TUC-4 immunoreactive granule cells significantly decreased in older subjects in comparison to younger cases. In contrast, no significant correlation with the age was present in the control group; particularly, neither a decrease in adult neurogenesis nor an increase of apoptotic granule cells was observed

within the dentate gyrus and age in control subjects (Table 3b).

\section{Inverse correlation of TUC-4 immunoreactive cells with age after HIE, but not in controls}

The density of immature TUC-4 immunoreactive granule cells was higher in younger subjects in comparison to older cases and correlated inversely with age of death of the subjects with HIE $(P=0.027)$ (Fig. 3; Table 3a). Although the density of calretinin-labeled granule cells also decreased with age, this correlation failed to reach statistical significance $(P=0.057) \quad$ (Table 3a). The expression pattern of TUC-4 and calretinin within the dentate gyrus in control cases without neuropathological abnormalities was not significantly influenced by age (Table 3b).

\section{No correlation of apoptotic granule cells with age}

The densities of apoptotic granule cells in both subjects with HIE and controls did not change significantly with age (Table 3a, b).

\section{Discussion}

The present study investigates the impact of HIE on adult neurogenesis and on neuronal apoptosis in the human hippocampal dentate gyrus. We found that the density of cells differentiating into the neuronal cell lineage, assessed by the expression of the early neuronal markers TUC-4 and calretinin, was higher in autopsy cases with cerebral hypoxia compared to control cases with normal brains. Furthermore, in contrast to controls, an inverse correlation between the density of TUC-4-labeled cells and age was detected in cases with HIE. In addition, the amount of apoptotic granule cells was also significantly increased in 


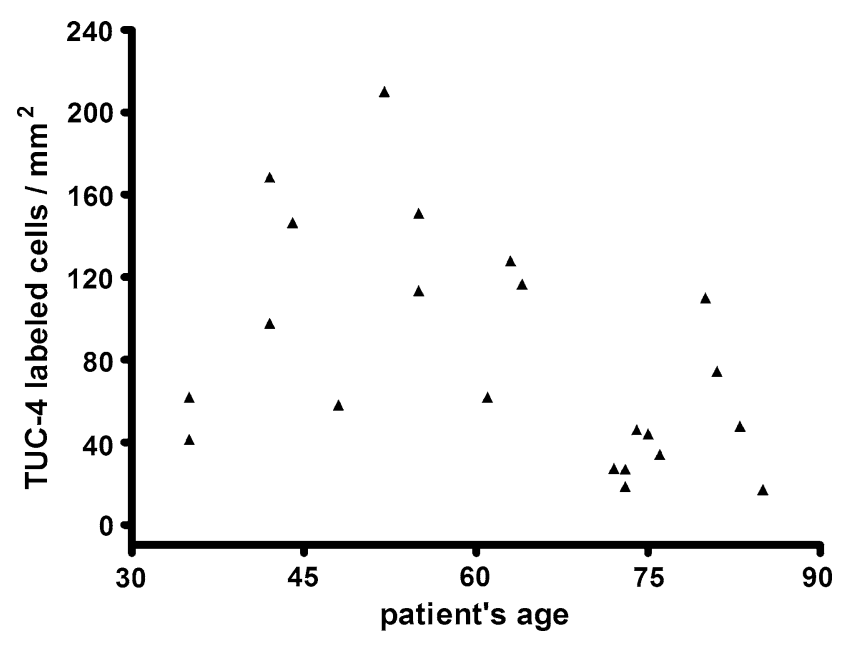

Fig. 3 Density of immature TUC-4 immunoreactive granule cells in the dentate gyrus related to the age at death in subjects with HIE, revealing an inverse correlation between the density of TUC-4-labeled cells and age $(P=0.027$, Spearman's rank correlation coefficient $=$ $-0.47)$. Although the density of calretinin-labeled granule cells also decreased with age, this correlation failed to reach statistical significance $(P=0.057$, Spearman's rank correlation coefficient $=-0.41)$

subjects with HIE compared to controls but no correlation with age was found.

Similar to our results, HIE induced by four vessel occlusion (4VO) resulted in a 2-3 times increase of adult neurogenesis in the hippocampal dentate gyrus of macaque monkeys [62], a 5-10 times increase in adult gerbils [55] and an increase of $14-27 \%$ in newborn rats [65], as detected by 5-bromo-2-deoxyuridine immunohistochemistry combined with different markers for neuronal differentiation. Furthermore, increased mitotic activity of both astrocytes and oligodendrocytes was found in neonatal rats after HIE [58]. In rats and macaque monkeys, the steps of neurogenesis after hypoxia and ischemia from stem cells to new granule cells were similar to the conditions in neurogenesis without exogenous stimuli [34, 37, 62, 63].

In addition to the dentate gyrus, human adult neurogenesis was also observed in the hippocampal CA1 region and in the olfactory bulb, even without previous stimulation [2, 21]. While the human neocortex was shown not to be an area of adult neurogenesis [3], the proliferation, neuronal differentiation and migration of newborn cells from the human subventricular zone is still a matter of debate [12, $15,52]$. An increase of adult neurogenesis was reported in the subventricular zone in macaque monkeys after $4 \mathrm{VO}$ [63]. Whether adult neurogenesis after HIE also occurs in the hippocampal CA1 region, the striatum and the neocortex is still controversial [47, 62, 63, 68, 69].

It has to be considered that variables such as different diseases or drug therapies may distinctly influence adult neurogenesis and that delays in the postmortal examinations may influence the quality of immunohistochemistry.
In the present study, analysis of the patients' records revealed that nine cases underwent corticosteroid therapy before death, and two other subjects suffered from depression. In seven cases, the autopsy revealed cancer, but the patients underwent neither cytostatic nor radiation therapy before death. In principle, any of these conditions could have interfered with adult neurogenesis [11, 37, 45, 59]. However, in the present study these cases were equally spread within the groups and comparisons regarding these parameters (absence or presence of corticosteroid therapy, depression, cancer revealed accidentally by autopsy) in HIE and control cases revealed no statistically significant differences. The interval from death to fixation of the autopsy material (0-5 days) and the age of the paraffin-embedded brain sections (3-11 years) (Tables 1,2 ) also did not substantially influence the density of immunoreactive cells.

In our study, the median density of PCNA-labeled cells was elevated after HIE, similar to what was noted for TUC4- and calretinin-immunoreactive cells. However, the increase of PCNA-labeled cells failed to reach statistical significance, whereas the density of TUC-4- and calretininlabeled cells was significantly increased in HIE cases. This discrepancy most probably was the result of a high interindividual variation of the densities of PCNA-labeled cells and, furthermore, may result from the different periods of the expression of these markers. Whereas PCNA is only expressed from the $\mathrm{G} 1$ phase to the $\mathrm{G} 2 / \mathrm{M}$ transition of cell division in humans [26], TUC-4 is expressed most probably between the first and the fourth week in rats $[36,50]$ and calretinin from the first to the sixth week after mitosis in mice $[5,49]$. We also tried to carry out immunohistochemistry for $\mathrm{Ki}-67$, nestin and calbindin, but these markers turned out not to be compatible with formalin-fixed, paraffin-embedded human brain tissue.

Regarding the dentate gyrus, there is debate about three presumptive functions of basal adult neurogenesis and enhanced adult neurogenesis: declarative memory [27], mood [11, 45] and recovery after impairment, but in both mammals and humans, areas where adult neurogenesis occurs do not fully recover function after damage [10, 13, 21, 29, 47].

In addition to an increased number of young neurons, an increase of apoptotic granule cells in the dentate gyrus was also observed in cases with HIE. This observation accords with previous data on autopsy cases with HIE [39]. In newborn rats, a similar effect was shown to be only transient after 4VO [65], suggesting that enhanced neuronal apoptosis after HIE probably occurs for a short time only. In this study $19.5 \%$ of all IST-labeled cells in HIE cases had the typical apoptotic morphology. The other IST-labeled cells were most probably dead or dying by necrosis or IST staining was a result of post-mortem DNA degradation. The increased dentate granule cell apoptosis after hypoxia may 
be one cause of memory impairment frequently observed in survivors after cerebral hypoxia [29, 39, 61].

With respect to the magnitude of adult neurogenesis in different age groups, in our study older-aged individuals without brain abnormalities showed neither a decrease in adult neurogenesis nor an increase of apoptotic neurons in the dentate gyrus compared to younger adult individuals. This supports the recent finding that hippocampal neurogenesis appears to remain relatively unaltered during healthy adulthood in rats [18], although a strong decrease of neurogenesis has been observed in older individuals of several other rodent species [9, 19, 25, 42].

In our study, older patients with a history of HIE showed approximately equal levels of hippocampal apoptosis compared to younger individuals with HIE. In contrast, after focal ischemia in aged rats, a larger number of apoptotic cells and an accelerated infarct development was observed in comparison to younger rats [40].

In conclusion, we show here that neurogenesis is increased in HIE. Although proliferation within the subgranular cell layer of the dentate gyrus appeared to remain relatively unaltered with age, older patients with a history of HIE appear to display a lower differentiation rate into neuronal cells. This may be of clinical importance since stimulation of adult neurogenesis by drugs or exercise may be less efficient in older human brains and could possibly impede functional recovery in older individuals.

Acknowledgments This investigation was supported by the Else Kröner-Fresenius-Stiftung. We thank Mrs. Christine Crozier for carefully editing the manuscript.

Conflict of interest statement The authors declare that they have no conflicts of interest.

Open Access This article is distributed under the terms of the Creative Commons Attribution Noncommercial License which permits any noncommercial use, distribution, and reproduction in any medium, provided the original author(s) and source are credited.

\section{References}

1. Altman J, Das GD (1965) Autoradiographic and histological evidence of postnatal hippocampal neurogenesis in rats. J Comp Neurol 124:319-335

2. Bédard A, Parent A (2004) Evidence of newly generated neurons in the human olfactory bulb. Brain Res Dev Brain Res 151:159168

3. Bhardwaj RD, Curtis MA, Spalding KL et al (2006) Neocortical neurogenesis in humans is restricted to development. Proc Natl Acad Sci 103:12564-12578

4. Booth CM, Boone RH, Tomlinson G, Detsky AS (2004) Is this patient dead, vegetative, or severely neurologically impaired? Assessing outcome for comatose survivors of cardiac arrest. JAMA 291:870-879

5. Brandt MD, Jessberger S, Steiner B et al (2003) Transient calretinin expression defines early postmitotic step of neuronal differentiation in adult hippocampal neurogenesis of mice. Mol Cell Neurosci 24:603-613

6. Chang A, Smith MC, Yin X, Fox RJ, Staugaitis SM, Trapp BD (2008) Neurogenesis in the chronic lesions of multiple sclerosis. Brain 131:2366-2375

7. Chen J, Zhang ZG, Li Y et al (2003) Statins induce angiogenesis, neurogenesis, and synaptogenesis after stroke. Ann Neurol 53:743-751

8. Chiaretti A, Antonelli A, Genovese O et al (2008) Intraventricular nerve growth factor infusion improves cerebral blood flow and stimulates doublecortin expression in two infants with hypoxicischemic brain injury. Neurol Res 30:223-238

9. Cowen DS, Takase LF, Fornal CA, Jacobs BL (2008) Age-dependent decline in hippocampal neurogenesis is not altered by chronic treatment with fluoxetine. Brain Res 1228:14-19

10. Darsalia V, Heldmann U, Lindvall O, Kokaia Z (2005) Stroke-induced neurogenesis in aged brain. Stroke 36:1790-1795

11. Dranovsky A, Hen R (2006) Hippocampal neurogenesis: regulation by stress and antidepressants. Biol Psychiatry 59:1136-1143

12. Eriksson PS, Perfilieva E, Bjork-Eriksson T et al (1998) Neurogenesis in the adult human hippocampus. Nat Med 4:13131317

13. Gerber J, Böttcher T, Bering J et al (2003) Increased neurogenesis after experimental Streptococcus pneumoniae meningitis. J Neurosci Res 73:441-446

14. Gold R, Schmied M, Giegerich G et al (1994) Differentiation between cellular apoptosis and necrosis by combined use of in situ tailing and nick translation techniques. Lab Invest 71:219-225

15. González-Martínez JA, Bingaman WE, Toms SA, Najm IM (2007) Neurogenesis in the postnatal human epileptic brain. J Neurosurg 107:365-628

16. Gross CG (2000) Neurogenesis in the adult brain: death of a dogma. Nat Rev Neurosci 1:67-73

17. Hastings N, Gould E (1999) Rapid extension of axons into the CA3 region by adult-generated granule cells. J Comp Neurol 413:146-154

18. Hattiangady B, Shetty AK (2008) Aging does not alter the number or phenotype of putative stem/progenitor cells in the neurogenic region of the hippocampus. Neurobiol Aging 29:129-147

19. Heine V, Maslam S, Joëls M, Lucassen P (2004) Prominent decline of newborn cell proliferation, differentiation, and apoptosis in the aging dentate gyrus, in absence of an age-related hypothalamus-pituitary-adrenal axis activation. Neurobiol Aging 25:361375

20. Jin K, Mao XO, Sun Y et al (2002) Heparin-binding epidermal growth factor-like growth factor: hypoxia-inducible expression in vitro and stimulation of neurogenesis in vitro and in vivo. J Neurosci 22:5365-5373

21. Jin K, Peel AL, Mao XO et al (2004) Increased hippocampal neurogenesis in Alzheimer's disease. Proc Natl Acad Sci 101:343347

22. Kaplan MS, Hinds JW (1977) Neurogenesis in the adult rat: electron microscopic analysis of light radioautographs. Science 197:1092-1094

23. Kawai T, Takagi N, Mochizuki N, Besshoh S, Sakanishi K, Nakahara M, Takeo S (2006) Inhibitor of vascular endothelial growth factor receptor tyrosine kinase attenuates cellular proliferation and differentiation to mature neurons in the hippocampal dentate gyrus after transient forebrain ischemia in the adult rat. Neuroscience 141:1209-1216

24. Kempermann G, Jessberger S, Steiner B, Kronenberg G (2004) Milestones of neuronal development in the adult hippocampus. Trends Neurosci 27:447-452

25. Kuhn HG, Dickinson-Anson H, Gage FH (1996) Neurogenesis in the dentate gyrus of the adult rat: age-related decrease of neuronal progenitor proliferation. J Neurosci 16:2027-2033 
26. Kurki P, Ogata K, Tan EM (1988) Monoclonal-antibodies to proliferating cell nuclear antigen (PCNA) cyclin as probes for proliferating cells by immunofluorescence microscopy and flowcytometry. J Immunol Methods 109:49-59

27. Leuner B, Gould E, Shors TJ (2006) Is there a link between adult neurogenesis and learning? Hippocampus 16:216-224

28. Lindvall O, Kokaia Z (2006) Stem cells for the treatment of neurological disorders. Nature 441:1094-1096

29. Madl C, Holzer M (2004) Brain function after resuscitation from cardiac arrest. Curr Opin Crit Care 10:213-217

30. Madl C, Kramer L, Domanovits H (2000) Improved outcome prediction in unconscious cardiac arrest survivors with sensory evoked potentials compared with clinical assessment. Crit Care Med 28:721-726

31. Manganas LN, Zhang X, Li Y et al (2007) Magnetic resonance spectroscopy identifies neural progenitor cells in the live human brain. Science 318:980-985

32. Martens P, Raabe A, Johnsson P (1998) Serum S-100 and neuronspecific enolase for prediction of regaining consciousness after global cerebral ischemia. Stroke 29:2363-2366

33. Mathews M, Bernstein R, Franza B, Garrels J (1984) Identity of the proliferating cell nuclear antigen and cyclin. Nature 309:374376

34. McDonald HY, Wojtowicz JM (2005) Dynamics of neurogenesis in the dentate gyrus of adult rats. Neurosci Lett 385:70-75

35. Minnerup J, Heidrich J, Wellmann J, Rogalewski A, Schneider A, Schäbitz WR (2008) Meta-analysis of the efficacy of granulocytecolony stimulating factor in animal models of focal cerebral ischemia. Stroke 39:1855-1861

36. Minturn JE, Fryer HJ, Geschwind DH, Hockfield S (1995) TOAD64, a gene expressed early in neuronal differentiation in the rat, is related to unc-33, a C. elegans gene involved in axon outgrowth. $\mathbf{J}$ Neurosci 15:6757-6766

37. Monje M, Vogel H, Masek M, Ligon K, Fisher P, Palmer TD (2007) Impaired human hippocampal neurogenesis after treatment for central nervous system malignancies. Ann Neurol 62:515-520

38. Nakatomi H, Kuriu T, Okabe S et al (2002) Regeneration of hippocampal pyramidal neurons after ischemic brain injury by recruitment of endogenous neural progenitors. Cell 110:429-444

39. Nau R, Haase S, Bunkowski S, Brück W (2002) Neuronal apoptosis in the dentate gyrus in humans with subarachnoid hemorrhage and cerebral hypoxia. Brain pathol 12:329-336

40. Popa-Wagner A, Badan I, Walker L, Groppa S, Patrana N, Kessler C (2007) Accelerated infarct development, cytogenesis and apoptosis following transient cerebral ischemia in aged rats. Acta Neuropathol 113:277-293

41. Quinn CC, Gray GE, Hockfield S (1999) A family of proteins implicated in axon guidance and outgrowth. J Neurobiol 41:158-164

42. Rao MS, Hattiangady B, Shetty AK (2006) The window and mechanisms of major age-related decline in the production of new neurons within the dentate gyrus of the hippocampus. Aging Cell 5:545-558

43. Reynolds BA, Tetzlaff W, Weiss S (1992) A multipotent EGFresponsive striatal embryonic progenitor cell produces neurons and astrocytes. J Neurosci 12:4565-4574

44. Rosser AE, Zietlow R, Dunnett SB (2007) Stem cell transplantation for neurodegenerative diseases. Curr Opin Neurol 20:166-192

45. Santarelli L, Saxe M, Gross C et al (2003) Requirement of hippocampal neurogenesis for the behavioral effects of antidepressants. Science 301:805-809

46. Schäbitz WR, Schneider A (2007) New targets for established proteins: exploring G-CSF for the treatment of stroke. Trends Pharmacol Sci 28:157-161

47. Schmidt W, Reymann KG (2002) Proliferating cells differentiate into neurons in the hippocampal CA1 region of gerbils after global cerebral ischemia. Neurosci Lett 334:153-156
48. Schmidt-Hieber C, Jonas P, Bischofberger J (2004) Enhanced synaptic plasticity in newly generated granule cells of the adult hippocampus. Nature 429:184-187

49. Schwaller B, Buchwald P, Blümcke I, Celio MR, Hunziker W (1994) Characterization of a polyclonal antiserum against the purified human recombinant calcium-binding protein calretinin. Cell Calcium 14:639-648

50. Seki T (2002) Expression patterns of immature neuronal markers PSA-NCAM, CRMP-4 and NeuroD in the hippocampus of young adult and aged rodents. J Neurosci Res 70:327-334

51. Seki T (2003) Microenvironmental elements supporting adult hippocampal neurogenesis. Anat Sci Int 78:69-78

52. Sgubin D, Aztiria E, Perin A, Longatti P, Leanza G (2007) Activation of endogenous neural stem cells in the adult human brain following subarachnoid hemorrhage. J Neurosci Res 85:1647-1655

53. Shapiro LA, Ribak CE (2004) Integration of newly born dentate granule cells into adult brains: hypotheses based on normal and epileptic rodents. Brain Res Rev 48:43-56

54. Shapiro LA, Upadhyaya P, Ribak CE (2007) Spatiotemporal profile of dendritic outgrowth from newly born granule cells in the adult rat dentate gyrus. Brain Res 1149:30-37

55. Sharp FR, Liu J, Bernabeu R (2002) Neurogenesis following brain ischemia. Brain Res Dev Brain Res 134:23-30

56. Shen J, Xie L, Mao X et al (2008) Neurogenesis after primary intracerebral hemorrhage in adult human brain. J Cereb Blood Flow Metab 28:1460-1468

57. Shingo T, Sorokan ST, Shimazaki T, Weiss S (2001) Erythropoietin regulates the in vitro and in vivo production of neuronal progenitors by mammalian forebrain neural stem cells. J Neurosci 21:9733-9743

58. Sizonenko SV, Camm EJ, Dayer A, Kiss JZ (2007) Glial responses to neonatal hypoxic-ischemic injury in the rat cerebral cortex. Int J Dev Neurosci 26:37-45

59. Tauber SC, Schlumbohm C, Schilg L, Fuchs E, Nau R, Gerber J (2006) Intrauterine exposure to dexamethasone impairs proliferation but not neuronal differentiation in the dentate gyrus of newborn common marmoset monkeys. Brain Pathol 16:209-217

60. The Hypothermia after Cardiac Arrest Study Group (2002) Mild therapeutic hypothermia to improve the neurologic outcome after cardiac arrest. N Engl J Med 346:549-556

61. Thömke F, Weilemann S (2007) Prognosis following cardiopulmonary resuscitation. Dtsch Arztebl 104 A-2879/B-2536/C-2460

62. Tonchev AB, Yamashima T (2006) Differential neurogenic potential of progenitor cells in dentate gyrus and CA1 sector of the postischemic adult monkey hippocampus. Exp Neurol 198:101-113

63. Tonchev AB, Yamashima T, Sawamoto K, Okano H (2005) Enhanced proliferation of progenitor cells in the subventricular zone and limited neuronal production in the striatum and neocortex of adult macaque monkeys after global cerebral ischemia. J Neurosci Res 81:776-788

64. Van Praag H, Schinder AF, Christie BR, Toni N, Palmer TD, Gage FH (2002) Functional neurogenesis in the adult hippocampus. Nat Neurosci 2:266-270

65. Vert P, Daval JL (2006) Cell death and neurogenesis after hypoxia: a brain repair mechanism in the developing rat? Bull Acad Natl Med 190:469-481

66. von Bohlen, und Halbach O (2007) Immunohistological markers for staging neurogenesis in adult hippocampus. Cell Tissue Res 329:409-420

67. Wijdicks EFM, Hijdra A, Young GB, Bassetti CL, Wiebe S (2006) Practice parameter: prediction of outcome in comatose survivors after cardiopulmonary resuscitation (an evidence-based review). Neurology 67:203-210

68. Yamashita T, Ninomiya M, Hernández Acosta P et al (2006) Subventricular zone-derived neuroblasts migrate and differentiate into 
mature neurons in the post-stroke adult striatum. J Neurosci 26:6627-6636

69. Yang Z, Covey MV, Bitel CL et al (2007) Sustained neocortical neurogenesis after neonatal hypoxic/ischemic injury. Ann Neurol 61:199-208

70. Zandbergen EGJ, de Haan RJ, Stoutenbeek CP, Koelman JHTM, Hijdra A (1998) Systematic review of early prediction of poor outcome in anoxic-ischemic coma. Lancet 352:1808-1812

71. Zandbergen EGJ, Hijdra A, Koelman JHTM for the PROPAC Study Group (2006) Prediction of poor outcome within the first 3 days of postanoxic coma. Neurology 66:62-68
72. Zeitzer MB (2005) Inducing hypothermia to decrease neurological deficit: literature review. J Adv Nurs 52:189-199

73. Zhang RL, Zhang Z, Zhang L, Wang Y, Zhang C, Chopp M (2006) Delayed treatment with sildenafil enhances neurogenesis and improves functional recovery in aged rats after focal cerebral ischemia. J Neurosci Res 83:1213-1219

74. Zhu DY, Liu SH, Sun HS, Lu YM (2003) Expression of inducible nitric oxide synthase after focal cerebral ischemia stimulates neurogenesis in the adult rodent dentate gyrus. J Neurosci 23:223239 